\title{
EFEITOS DA MUDANÇA DE USO DA TERRA NO MUNICÍPIO DE ILHA SOLTEIRA - SP, BRASIL
}

\author{
Alice Nardoni Marteli ${ }^{1}$
}

José Augusto de Lollo ${ }^{2}$

\begin{abstract}
RESUMO
Mudanças de uso da terra são comumente o mecanismo desencadeador de processos de degradação ambiental. O trabalho avalia mudanças de uso da terra ocorridas no município de llha Solteira nos últimos quarenta anos e seus efeitos nos processos de degradação ambiental identificados na área. O uso da terra foi classificado a partir de imagens Landsat de 1975 e 2014 usando-se o módulo Makesig para obtenção das assinaturas espectrais e treinamento e o módulo Maxlike para classificação das imagens no SIG Idrisi Selva. As mudanças nos padrões de uso da terra identificadas foram decorrentes de expansão urbana e de atividades agrícolas. Combinadas às condições de solos da área, tais mudanças têm sido responsáveis pelo desenvolvimento de processos erosivos e por indícios de degradação dos mananciais superficiais.
\end{abstract}

PALAVRAS-CHAVE: Uso e ocupação da terra. Degradação ambiental. Sensoriamento Remoto.

\section{EFFECTS OF LAND USE CHANGE IN ILHA SOLTEIRA DISTRICT - SP, BRAZIL}

\section{ABSTRACT}

Land use change is the main mechanism causing Environmental degradation. This article evaluates land use changes in Ilha Solteira District in the paste forty years and its effects in environmental degradation in the area. Land use was classified from 1975 e 2014 Landsat Imagery using Makesig module for spectral signature and training, and Maxlike module for imagery classification(both from Idrisi Selva). Land use changes identified were

\footnotetext{
${ }^{1}$ Geógrafa, Mestranda em Engenharia Civil, UNESP-FEIS. E-mail: alicenmart@gmail.com

${ }^{2}$ Geólogo, Professor Titular, UNESP-FEIS. E-mail: lolloja@dec.feis.unesp.br
} 
Revista Nacional de

Gerenciamento de Cidades

due to urban expansion and farming. Associated with soil conditions in the area, land use change were responsible by erosion processes and water quality compromising evidences.

KEY-WORDS: Land use. Environmental degradation. Remote Sensing.

\section{EFECTOS DE CAMBIOS EM USO DE LA TIERRA EM ILHA SOLTEIRA - SP, BRASIL}

\section{RESUMEN}

Los cambios en el uso de la tierra son responsables por la activación de procesos de degradación del medio ambiente. El estudio evalúa los cambios en el uso ocurridos en Ilha Solteira en los últimos 40 años, y sus efectos en los procesos de degradación del medio. El uso de la tierra se clasificó de imágenes del satélite Landsat de 1975 y 2014 con la herramienta Makesig para obtener registros espectrales y para lo entrenamiento del proceso, así como la Maxlike para la clasificación de las imágenes en el SIG Idrisi Selva. Los cambios identificados fueran debido a la expansión urbana y las actividades agrícolas. Junto con las condiciones de los suelos, esos cambios han sido responsables por los procesos de erosión y la degradación de la calidad de las aguas.

PALABRAS-CLAVE Uso de la tierra. Degradación ambiental. Detección remota.

\section{INTRODUÇÃO}

O crescimento urbano provoca alterações no ambiente que podem impactar negativamente o meio físico, pois no processo de urbanização, o espaço urbano existente é ocupado, construído, destruído, transformado, sempre trazendo modificações à nossa paisagem (FERREIRA; FRANCISCO, 2003). O mesmo pode ocorrer também com alterações nos padrões de ocupação e produção no meio rural.

Além disso, quando o processo de expansão urbana direcionado pelos interesses econômicos não acompanha um planejamento efetivo que considere as características do meio físico ocorre, muitas vezes, a ocupação de locais desfavoráveis à ocupação, promovendo um desequilíbrio ambiental dessas áreas (ROSSINI, 2001). 
Assim, dependendo das características geológicas e de relevo, a forma de ocupação do território pode vir a provocar situações de risco. No entanto, se a instalação dos núcleos urbanos e o uso dos espaços naturais forem feitos respeitando as condicionantes do meio físico, os impactos são menores e os riscos podem ser minimizados (PEJON; RODRIGUES; ZUQUETTE, 2013).

Dentre os impactos existentes, há problemas de erosão e o consequente assoreamento, que causa dentre outros fatores, alteração da cobertura vegetal, modificação do leito dos rios e perca da qualidade do solo e da água.

No município de llha Solteira, assim como em toda a região noroeste do Estado de São Paulo, não houve a visão preservacionista no desenvolvimento da região, sendo predominante a ocupação desordenada dos solos, inclusive das áreas de proteção dos mananciais, em favor da expansão da fronteira agrícola e da pecuária (MANOEL, 2013).

Tais efeitos podem ser notados também nas áreas de expansão urbana do município, onde os problemas de degradação ambiental estão quase sempre relacionados à intervenção humana (VIVANCO; LOLLO; LORANDI, 2014).

Considerando tal conjunto de fatores, o presente trabalho teve como objetivo avaliar como as mudanças de uso da terra ocorridas nos últimos quarenta anos no município de llha Solteira - SP, Brasil se deram e sua relação com os processos de degradação dos recursos naturais.

\section{DESENVOLVIMENTO}

\subsection{CARACTERIZAÇÃO DA ÁREA DE ESTUDO}

O município de llha Solteira está localizado no extremo noroeste do Estado de São Paulo, Brasil (Figura 1), a $680 \mathrm{~km}$ da capital, na divisa com o Estado do Mato

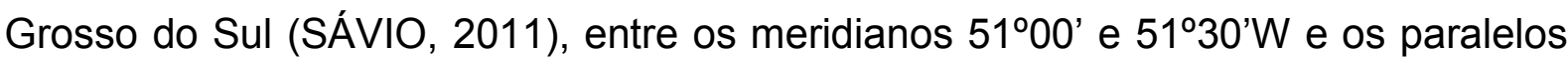
$20^{\circ} 15^{\prime}$ e $20^{\circ} 45^{\prime} \mathrm{S}$, em uma área territorial de $652,449 \mathrm{~km}^{2}$ (IBGE, 2014). 
Revista Nacional de

Gerenciamento de Cidades

Figura 1: Localização da área de estudo no Estado de São Paulo, Brasil
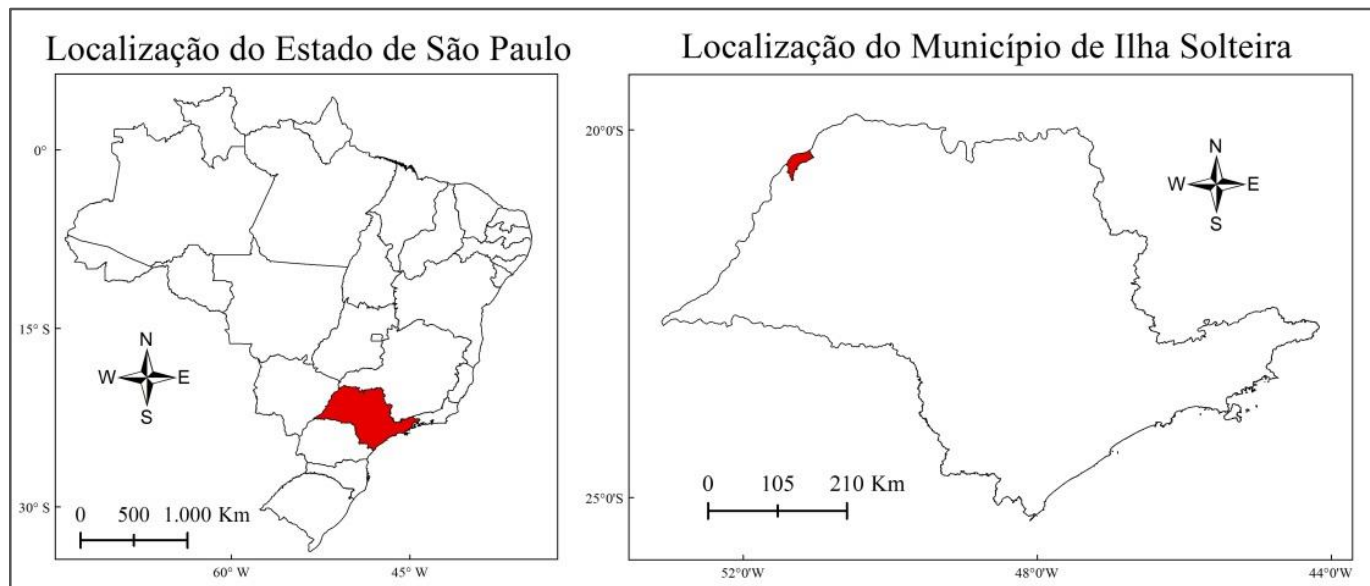

Elaboração: Alice Nardoni Marteli Orientação: José Augusto de Lollo

Datum Horizontal: SIRGAS 2000

Fonte: Malhas Digitais IBGE

Laboratório de Geotecnia, UNESP - FEIS, Março, 2014.

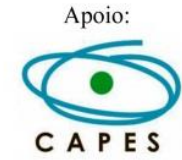

Lollo (1998) descreve o relevo da área como ondulado a suavemente ondulado, pouco dissecado, composto por colinas amplas e médias com baixa declividade e vales amplos.

Ao longo da extensão municipal encontram-se Latossolos Vermelhos, Argissolos Vermelhos e Argissolos Vermelhos-Amarelos (OLIVEIRA et al., 1999). Tais solos apresentam texturas arenosas e médias e estrutura dispersa.

O município de llha Solteira encontra-se entre os Rios Paraná, Tietê e São José dos Dourados sob o Aquífero Bauru-Caiuá, que apresenta como características ser poroso, livre a semiconfinado (SANTOS, 2014).

Segundo a classificação de Köppen, o clima varia do tipo Cwa a Aw (CINDIRU, 1995; LOLLO, 1998). O tipo Cwa, que abrange toda a parte central do Estado de São Paulo é caracterizado pelo clima tropical de altitude, com chuvas no verão e seca no inverno, com a temperatura média do mês mais quente superior a $22^{\circ} \mathrm{C}$. As regiões localizadas a noroeste do Estado de São Paulo são mais quentes e 
Revista Nacional de

Gerenciamento de Cidades

por isso, pertencem ao tipo Aw, tropical chuvoso com inverno seco e ameno, e mês mais frio com temperatura média superior a 18ํㅡ (CEPAGRI, 2013).

De acordo com os estudos feitos pela CESP para o licenciamento ambiental da Usina Hidrelétrica de Ilha Solteira, a vegetação predominante na região é a Floresta Estacional Semidecídua, que faz parte do Domínio da Mata Atlântica, com as feições Floresta Estacional Semidecídua Submontana, nas áreas mais elevadas, e Floresta Estacional Semidecídua Aluvial, também chamada de mata ciliar, disposta ao longo dos cursos d'água (DIAS, 2014). Tais vegetações também são chamadas de mata úmida e mata seca (SILVA et al., 2006). Há também zonas de contato entre os biomas Mata Atlântica e Savana (cerrado), onde ocorre a formação Savana Arbórea Densa, ou cerradão (DIAS, 2014).

No município, a maior parte dessa cobertura original foi eliminada com a ocupação da área (LOLLO, 1998; SILVA et al., 2006).

De acordo com o levantamento feito por Lima, Silva e Altimare (2004) os principais usos da terra no município de llha Solteira na época eram pastagens, corpos d'água, áreas urbano-rurais, culturas anuais, vegetação ciliar, culturas perenes, fragmentos de mata e área urbana respectivamente.

Cabe destacar que os cursos d'água existentes no município encontram-se praticamente desprovidos de mata ciliar (CRUZ, 2008).

Ao analisar os impactos do crescimento urbano no município, Ortega (2011) verificou que uma das mudanças mais notórias foi no uso e ocupação dos solos, onde antes predominavam os pastos e atualmente existem cultivos de grandes extensões de cana de açúcar, com trabalhos mecanizados significativa perda de solo.

Ao realizar um levantamento do toda a área do município de llha Solteira, Vivanco, Lollo e Lorandi (2014) analisaram a evolução dos processos erosivos na área de expansão urbana e constaram que o processo de ocupação da área tem favorecido o surgimento de processos erosivos que tendem a carrear materiais que podem comprometer a qualidade dos córregos próximos. 


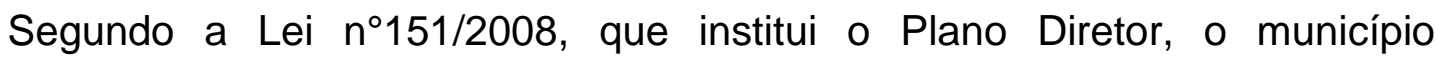
apresenta normas relativas ao desenvolvimento urbano que levem em conta a proteção e melhoria ambiental e a utilização adequada do espaço territorial e dos recursos hídricos, mediante criteriosa definição do uso e ocupação da terra, promovendo desta forma, a recuperação e a revitalização de áreas degradadas e proteção dos recursos hídricos e matas ciliares, prevenção de enchentes, inundações urbanas, erosões do solo, queimadas e desmatamentos (ILHA SOLTEIRA, 2008).

No entanto, a maioria destas normas não têm resultado o controle esperado nos processos de degradação ambiental, pois têm desconsiderado os atributos do meio físico.

\subsection{PROCEDIMENTOS METODOLÓGICOS}

Este trabalho é resultante de uma pesquisa preliminar e foi realizado com base em revisão bibliográfica, levantamento de dados anteriores sobre degradação ambiental na área e fundamentos de sensoriamento remoto para a montagem do banco de dados, os quais foram tratados no SIG Idrisi Selva.

Os materiais utilizados foram imagens históricas dos satélites Landsat, do período de 1975 a 2014, e dados de sites oficiais, como IBGE (http://mapas.ibge.gov.br/) e Prefeitura Municipal (http://www.ilhasolteira.sp.gov.br/).

Para analisar as mudanças no uso da terra no município de llha Solteira foram obtidas imagens dos satélites Landsat 1, para o ano de 1975 disponível gratuitamente no catálogo de imagens do INPE (http://www.dgi.inpe.br/CDSR/) e Landsat 8, para o ano de 2014 disponível gratuitamente no catálogo de imagens da USGS (http://earthexplorer.usgs.gov/).

O ano de 1975 foi escolhido por ser a data mais próxima da implantação do núcleo urbano de Ilha Solteira (1970) da qual se dispunha de uma imagem de 
satélite com boa qualidade e baixa cobertura de nuvens de forma a permitir uma classificação de usos fiel à realidade da época.

A partir da sequência de procedimentos representada na Figura 2, foram elaboradas as classificações de uso e ocupação da terra para os anos históricos de interesse. Os procedimentos foram desenvolvidos no SIG Idrisi Selva.

Figura 2: Sequência de procedimentos utilizada na classificação das imagens

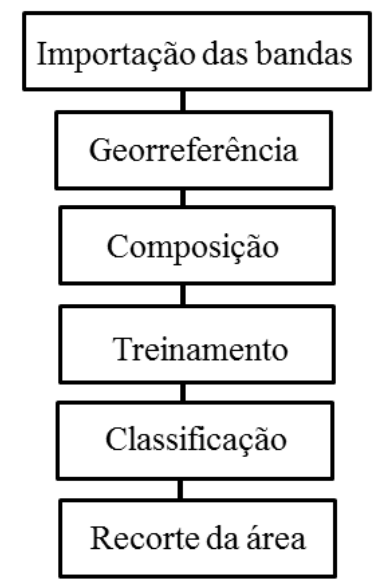

\subsection{RESULTADOS E DISCUSSÕES}

Os percentuais de cada tipo de uso da terra considerado nas duas datas são apresentados na Figura 3. As classificações de uso e ocupação da terra, obtidas para os dois anos considerados, são apresentadas na Figura 4, onde podem ser notadas as mudanças em padrões de uso entre as duas imagens. 


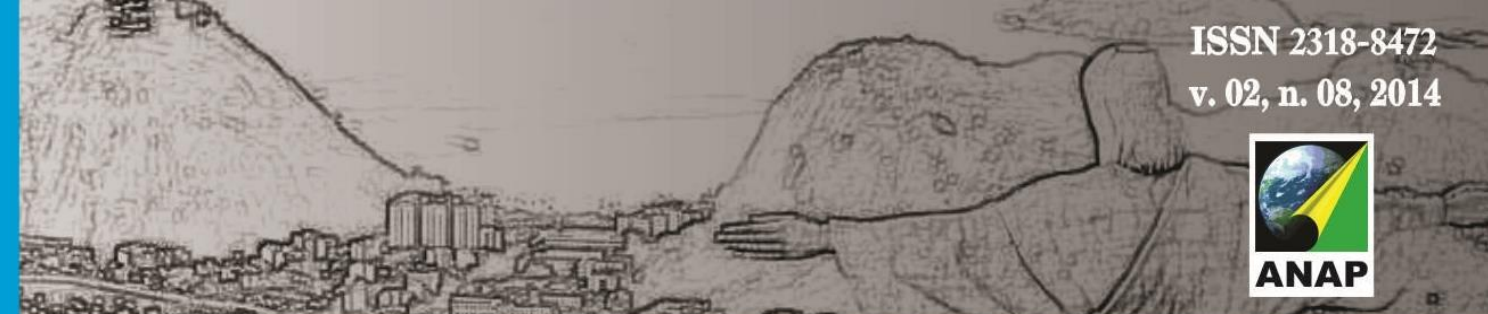

Revista Nacional de

Gerenciamento de Cidades

Figura 3: Percentuais de uso e ocupação da terra na área (1975 e 2014)

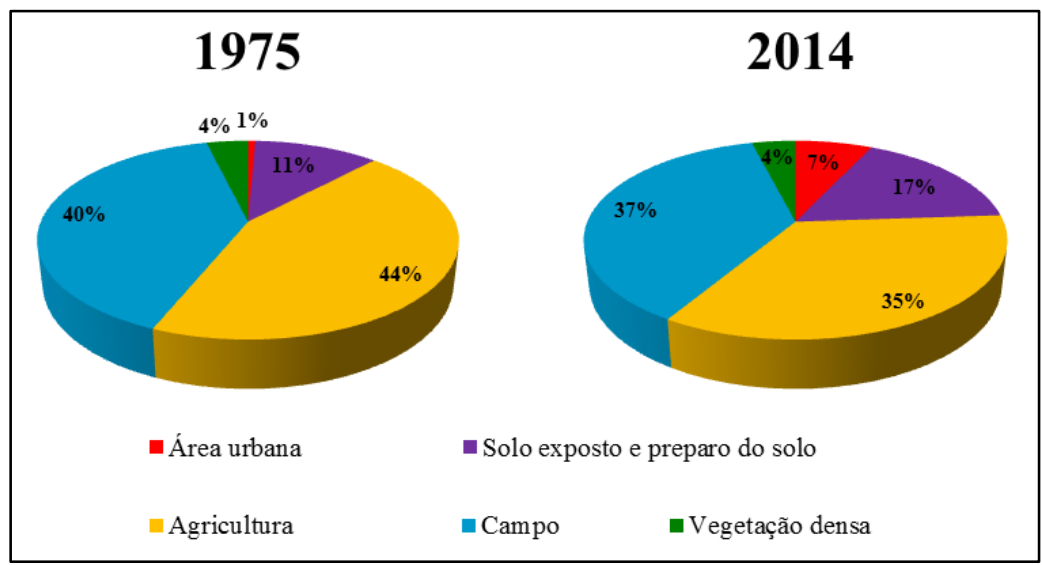

Figura 4: Classificações de uso e ocupação da terra no Município de Ilha Solteira (1975 e 2014)

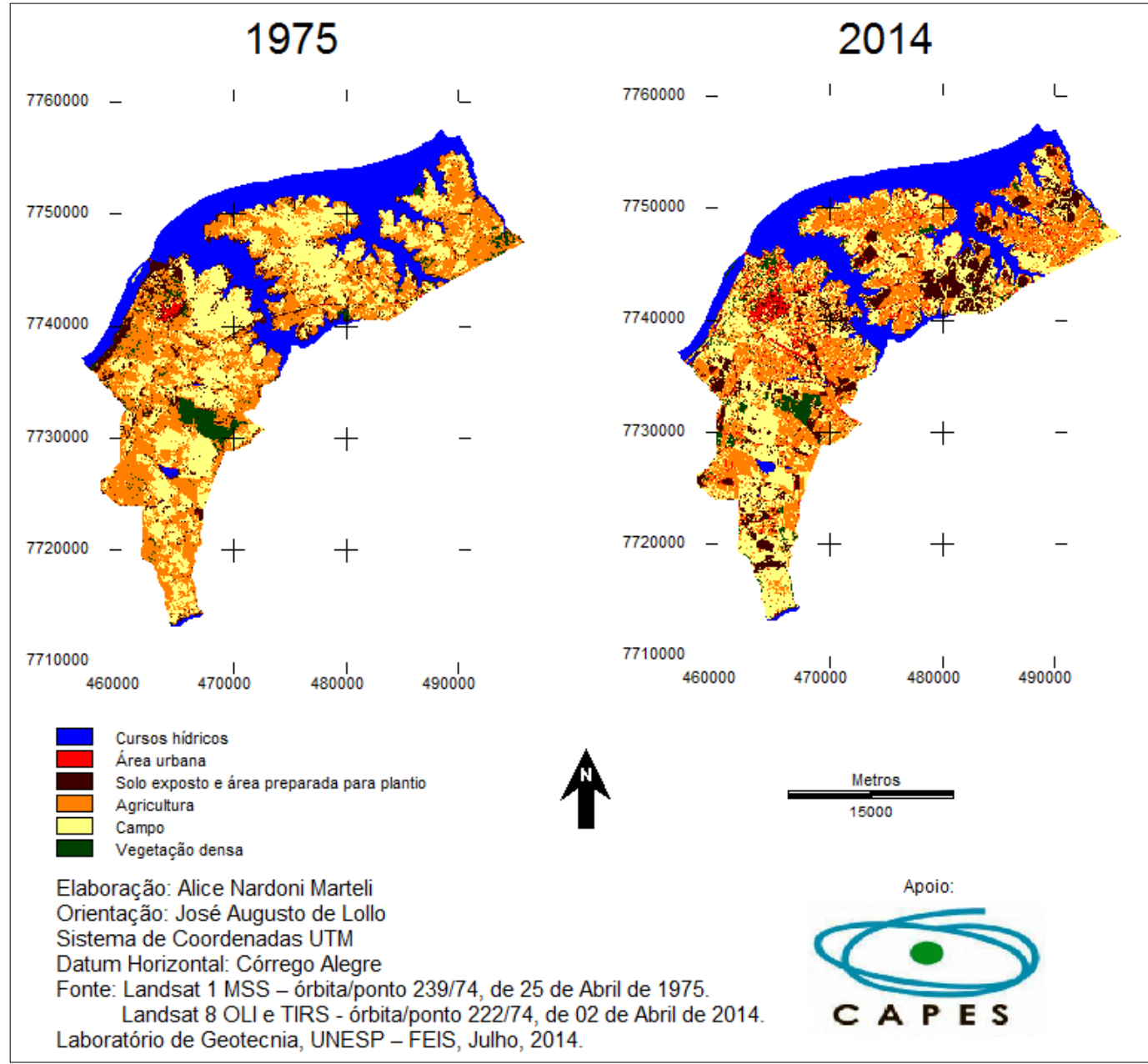


Como se pode observar, houve um aumento significativo da ocupação urbana na área (de 1 a 7\%), o qual foi acompanhado de aumento significativo da cobertura da terra pela classe solo exposto ( 11 a 17\% da área), o que evidencia maior ocupação antrópica, seja pela prática agrícola, seja pela urbanização.

Tais mudanças foram acompanhadas da redução nos percentuais das classes de uso campo e agricultura (40 para 37\%, e 44 para 35\%, respectivamente).

São processos claramente relacionados, uma vez que a expansão urbana se deu sobre áreas de pastoreio (campo) e de agricultura representada por pequenas propriedades rurais, o que significa um grande potencial de surgimento de processos erosivos, por se tratarem de áreas com solos arenosos e de baixa compacidade, portanto bastante erodíveis, e que no processo de inicial de urbanização ficam expostos à ação da chuva em função da remoção da vegetação rasteira e da implantação da infraestrutura urbana nem sempre adequada às condições recentes da área.

Em termos percentuais se observa a manutenção das áreas de vegetação densa, porém houve significativa remoção de matas ciliares em alguns pontos, especialmente próximos à área urbana, que foi acompanhada pela expansão de áreas de vegetação densa em certas parcelas rurais.

Gonzaga et. al. (2007) caracterizaram a qualidade da água em cinco pontos no Córrego Sem Nome (afluente do Córrego Caçula na porção noroeste da Bacia). Destes, três pontos apresentaram variações importantes nos parâmetros de turbidez e sólidos totais dissolvidos, sendo que em dois valores de turbidez foram superiores a $35 \mathrm{NTU}$ e num dos pontos o valor de sólidos totais dissolvidos foi superior a $800 \mathrm{mg} / \mathrm{L}$, revelando redução na qualidade da água.

Dentre os pontos com variações significativas de turbidez, dois se situam em áreas com solo exposto e um em área de expansão urbana, sendo o maior valor encontrado no ponto de amostragem próximo à área de expansão urbana. O mesmo 
Revista Nacional de

Gerenciamento de Cidades

ocorre com relação ao ponto com maior valor de sólidos totais dissolvidos no córrego.

Avaliando a qualidade da água do córrego do Ipê (que se situa em uma das áreas urbanizadas descontínuas do município, chamado Bairro do Ipê), Santos (2012) determinou valor de 150 NTU para turbidez interpretando tal resultado como consequência de erosão em chácaras na área, e um valor de 183 NTU em outro ponto próximo a uma voçoroca.

Segundo Santos (2012), os valores de sólidos totais superiores a os 80 $\mathrm{mg} \cdot \mathrm{L}^{-1}$, são consequência de maior carreamento de sedimentos no período chuvoso. Ainda segundo o autor, mesmo com parte da mata ciliar preservada, as atividades de manejo do solo para cultivo de cana de açúcar favorecem o carreamento de sedimentos.

Essa área corresponde exatamente à área de ocorrência do relevo com colinas convexas e solos arenosos de baixa compacidade, onde já haviam sido identificados processos erosivos bastante antigos, que foram recentemente reativados em função do lançamento mal dimensionado da rede de drenagem urbana.

Lollo e Vivanco (2014) destacam que a expansão urbana tem resultado processos erosivos acelerados que tem sido responsáveis pela redução da qualidade dos recursos hídricos nos córregos próximos à área urbana do município.

Os autores alertam ainda que a recente expansão do uso agrícola para cultivo de cana de açúcar pode intensificar ainda mais o processo se não forem adotadas práticas de manejo adequadas.

Isso coincide com situação já verificada por Vivanco, Lollo e Lorandi (2014), relacionando a ocupação urbana inadequada com o surgimento de processos erosivos ao longo da área de expansão urbana e próxima aos cursos hídricos.

Assim, além dos processos comuns de degradação física do solo - erosão, compactação e perda de solo - a expansão urbana pode gerar impactos indiretos na 
vegetação e na qualidade das águas superficiais, tornando sérios problemas ambientais.

Medidas preventivas devem ser aderidas pelos órgãos gestores para controle da degradação do meio físico. Dentre tais medidas, destacam-se a manutenção da cobertura vegetal do solo, como a reconstituição e a conservação de matas ciliares.

Nesse sentido, Ortega (2011) propõe para o município de llha Solteira técnicas de manejo como curvas de nível, para diminuir e evitar erosões, além do carregamento de adubos e nutrientes do solo. Também propõe a implantação de sistemas agroflorestais onde se intercalam num mesmo espaço, culturas perenes, anuais, e animais domésticos para produção, reduzindo assim os níveis de erosão.

Paralelamente há outras medidas, consideradas de longo prazo, como o incentivo de cursos de extensão voltados para a educação ambiental, como propostos por Manoel (2013).

Dessa forma, estudos que permitam a avaliação dos efeitos da mudança da terra pelo fator antrópico são cada vez mais procurados por órgãos interessados no planejamento e gestão ambiental de municípios e bacias hidrográficas, uma vez que o crescimento urbano descontrolado e a ocupação sem planejamento em áreas de risco, afeta milhares de pessoas e causa prejuízos sociais e econômicos cada vez mais severos.

\section{CONCLUSÃO}

Os processos de degradação ambiental significativos na área estudada estão fortemente relacionados às mudanças de padrões de uso e ocupação da terra, em particular à expansão urbana que tem acarretado processos erosivos resultando evidências de degradação do solo e dos recursos hídricos superficiais. 


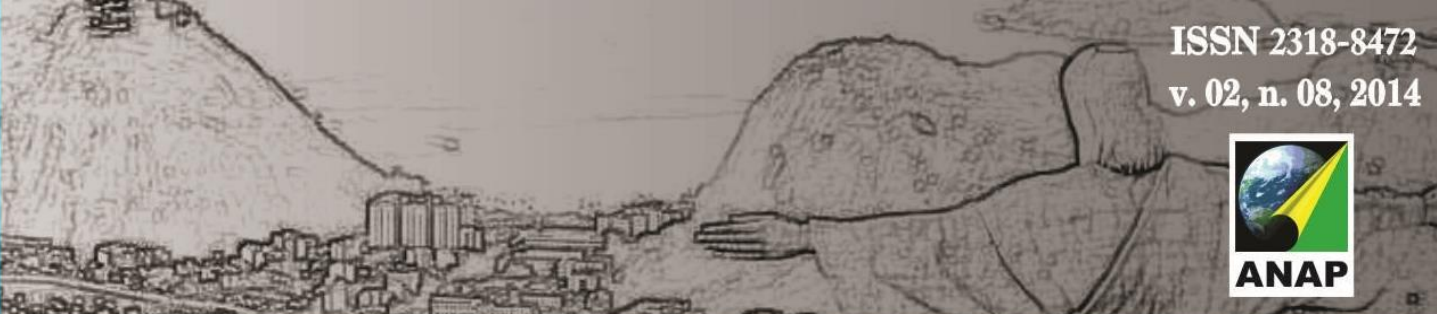

Revista Nacional de

Gerenciamento de Cidades

\section{AGRADECIMENTOS}

Os autores agradecem a CAPES pela bolsa de pesquisa concedida à autora, e à FAPESP pela infraestrutura disponibilizada pelo Auxílio à Pesquisa (Processo 2012/07842-4).

\section{REFERÊNCIAS}

CEPAGRI - Centro de pesquisas meteorológicas e climáticas aplicadas à agricultura. Clima dos Municípios Paulistas. Campinas: UNICAMP, 2013. Disponível em:

<http://www.cpa.unicamp.br/outras-informacoes/clima-dos-municipios-paulistas.html>. Acesso em: 28 abr. 2013.

CINDIRU - Consórcio Intermunicipal para o Desenvolvimento da Irrigação na Região de Urubupungá. Minuta do termo de Referência para o Estudo de Viabilidade Técnica, Econômica e Social para o desenvolvimento da Agricultura Irrigada na Região de Urubupungá. Ilha Solteira, 1995. 32p.

CRUZ, S.P. Avaliação da degradação do meio físico por áreas de empréstimo usando Geoindicadores e Sistema de Informações Geográficas - área urbana de llha Solteira (SP). Ilha Solteira, 2008. 161p. Dissertação (Mestrado em Engenharia Civil), Faculdade de Engenharia de llha Solteira - UNESP, Ilha Solteira, 2008. Disponível em:

<http://www.athena.biblioteca.unesp.br/exlibris/bd/bis/33004099084P5/2008/cruz_sp_me_ilha.pdf $>$. Acesso em: 13 abr. 2014.

DIAS, J. H. P. <joao.dias@cesp.com.br>. Duvidas vegetação llha. 16 de Abril de 2014. E-mail para: Alice Nardoni Marteli <alicenmart@gmail.com>.

FERREIRA, R. C.; FRANCISCO, J. A legislação ambiental e urbanística no trato das fronteiras d'água. In.: BRAGA, R. CARVALHO, P. F. (Org.). Recursos Hídricos e Planejamento Urbano e Regional. Rio Claro, Deplan-IGCE-UNESP, 2003, 131p.

GONZAGA, M.L.; CARVALHO, A.G.B., LOLLO, J.A.; MATSUMOTO, T. Uso e ocupação do solo e qualidade da água de mananciais superficiais: Córrego Caçula, Ilha Solteira (SP). In: SIMPÓSIO BRASILEIRO DE CARTOGRAFIA GEOTÉCNICA E GEOAMBIENTAL, 7, 2007, Maringá. Anais... Maringá: ABGE, 2007. CD-ROM.

IBGE - Instituto Brasileiro de Geografia e Estatística. Cidades@ 2014. Disponível em: <http://www.cidades.ibge.gov.br/xtras/perfil.php?lang=\&codmun=352044>. Acesso em: 13 abr. 2014.

ILHA SOLTEIRA. Lei n¹51de 01 de Julho de 2008. Lei Complementar: Institui o Plano Diretor do Município de llha Solteira, cria o Conselho da Cidade e dá outras providências. Ilha Solteira:

Prefeitura Municipal de Ilha Solteira. Disponível em:

<http://www.ilhasolteira.sp.gov.br/planodiretor/images/Leic-151.pdf/>. Acesso em: 13 jul. 2014. 


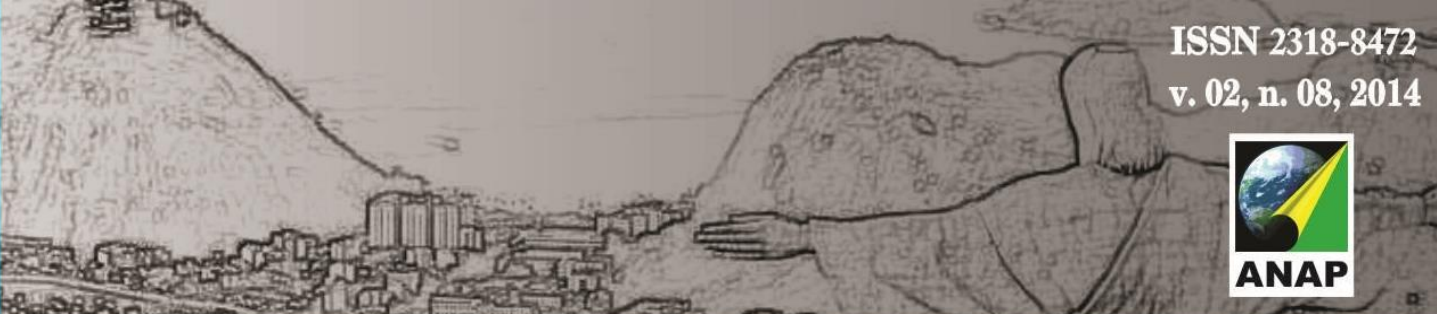

Revista Nacional de

Gerenciamento de Cidades

LIMA, E. A. C. F.; SILVA, H. R.; ALTIMARE, A. L. Uso atual da terra no Município de llha Solteira, SP: riscos ambientais associados. Holos Environment (CD-ROM), CEA-UNESP, v. 4, n.2, p. 81-96, 2004.

LOLLO, J. A. Caracterização geotécnica da área de expansão urbana de llha Solteira (SP) com o uso de formas de relevo. In: SIMPÓSIO BRASILEIRO DE CARTOGRAFIA GEOTÉCNICA, 3, 1998, Florianópolis. Anais... Florianópolis: ABGE, 1998. CD-ROM.

LOLLO, J. A.; VIVANCO, J.M.C. Erosion Processes and Water Quality in Caçula Stream Watershed (Ilha Solteira - SP, Brazil). In: IAEG CONGRESS 2014, 12, 2014, Torino. Proceedings... Torino: IAEG, 2014. CD-ROM.

MANOEL, L. O. Avaliação e monitoramento da qualidade da água na microbacia do córrego Caçula no Município de llha Solteira-SP. . Dissertação (Mestrado em Engenharia Civil) Faculdade de Engenharia de Ilha Solteira - UNESP, Ilha Solteira, 2013. 167f. Disponível em:

$<$ http://www.feis.unesp.br/Home/departamentos/engenhariacivil/pos-graduacao/2013_leticia.pdf>. Acesso em: 24 abr. 2014.

OLIVEIRA, J. B. et al. Mapa pedológico do estado de São Paulo: legenda expandida. Campinas: EMBRAPA, 1999. Escala 1:500.000.

ORTEGA, D. J. P. Avaliação dos efeitos das atividades antrópicas na bacia hidrográfica do Córrego do Ipê, município de Ilha Solteira - SP. Dissertação (Mestrado em Engenharia Civil) Faculdade de Engenharia de Ilha Solteira - UNESP, Ilha Solteira, 2011. 151f. Disponível em: $<$ http://www.feis.unesp.br/Home/departamentos/engenhariacivil/pos-graduacao/2011_diego.pdf>. Acesso em: 23 jul. 2014.

PEJON, O. J.; RODRIGUES, V. G. S.; ZUQUETTE, L. V. Impactos Ambientais sobre o solo. In: CALIJURI, M. C.; CUNHA, D. G. F. Engenharia Ambiental: conceitos, tecnologia e gestão. Rio de Janeiro: Elsavier, 2013. p.317-343.

ROSSINI, D. Análise Ambiental e do Padrão Espacial em Áreas de Expansão Urbana de Limeira - SP. Dissertação (Mestrado em Geografia) - Instituto de Geociências e Ciências Exatas - UNESP, Rio Claro, 2001, 171 f.

SANTOS, F. M. dos. Caracterização do meio físico da Bacia do Córrego Caçula e processos de degradação associados com vistas ao planejamento territorial. Dissertação (Mestrado em Engenharia Civil) - Faculdade de Engenharia de llha Solteira, - UNESP, Ilha Solteira, 2014, $123 f$. Disponível em: <http://www.feis.unesp.br/Home/departamentos/engenhariacivil/posgraduacao/2014_franciane.pdf>. Acesso em: Acesso em: 14 mar. 2014.

SANTOS, G.O. Uso e ocupação do solo e monitoramento dos recursos hídricos na Microbacia do Córrego do Ipê, Ilha Solteira, S.P. Dissertação (Mestrado em Agronomia) - Faculdade de Engenharia de Ilha Solteira, - UNESP, Ilha Solteira, 2012. $162 \mathrm{f}$.

SÁVIO, F. llha Solteira, um sonho, uma história. São José do Rio Preto: THS, 2011. 195p. Disponível em: <http://www.ilhasolteira.com.br/emancipacao/>. Acesso em: 13 abr. 2014.

SILVA, H. R. et al. Sensoriamento remoto na identificação do uso e ocupação da terra na área do projeto "conquista da água", Ilha Solteira - SP, Brasil. Eng. Agríc., Jaboticabal, v.26, n.1, p.328-334, jan./abr. 2006. Disponível em: <http://www.scielo.br/pdf/eagri/v26n1/30124.pdf>. Acesso em: 17 abr. 2014. 
Revista Nacional de

Gerenciamento de Cidades

VIVANCO, J.M.C.; LOLLO, J. A.; LORANDI, R. Processos erosivos e qualidade de água na área de expansão urbana de Ilha Solteira (Brasil). In: CONGRESSO LUSO-MOÇAMBICANO DE ENGENHARIA, 7., 2014, Inhambane. Anais... Inhambane: UEM, 2014. CD-ROM. 